\title{
CONCEPÇÃO DOS PROFESSORES DE BIOLOGIA DAS ESCOLAS ESTADUAIS DO MUNICÍPIO DE PLANALTO-PR, QUANTO A UTILIZAÇÃO DE MODELOS DIDÁTICOS COMO FERRAMENTA PARA O ENSINO DE GENÉTICA
}

\author{
Gabriela Maria Welter ${ }^{1}$ \\ Vanessa Silva Retuci ${ }^{2}$ \\ Izabel Aparecida Soares ${ }^{3}$
}

\begin{abstract}
Resumo: A disciplina de Biologia tem sido apontada pelos alunos como sendo complexa. Tal fato normalmente é atribuído aos conceitos e conteúdos complexos, mas muitas vezes é o reflexo da falta de metodologias variadas para o ensino, principalmente da genética. Na tentativa de minimizar as dificuldades, alternativas podem contribuir no processo de ensino e aprendizagem, dentre elas, a utilização de modelos didáticos. Neste trabalho foi analisada a importância do uso de modelos didáticos para o ensino de genética, partindo da perspectiva dos professores de biologia das escolas estaduais do município de Planalto-PR. Inicialmente foram construídos três modelos didáticos para disponibilizar aos professores, os quais foram utilizados para trabalhar os conteúdos que eles elencaram como sendo de maior complexidade. Os modelos foram utilizados em sala de aula, e os envolvidos relataram a validade dos recursos como estratégias didáticas, auxiliando no entendimento dos conteúdos, bem como resgatando nos estudantes a participação durante as aulas.
\end{abstract}

Palavras-Chave: Genética, Recurso Didático, Aprendizagem Lúdica.

\section{CONCEPTION OF THE TEACHERS OF BIOLOGY OF THE STATE SCHOOLS OF THE MUNICIPALITY OF PLANALTO-PR, AS WELL AS THE USE OF DIDACTIC MODELS AS A TOOL FOR THE TEACHING OF GENETICS}

\begin{abstract}
The discipline of Biology has been pointed out by the students as being complex. This is usually attributed to complex concepts and content, but is often a reflection of the lack of varied methodologies for teaching, especially genetics. In an attempt to minimize difficulties, alternatives may contribute to the teaching and learning process, among them, the use of didactic models. In this work the importance of the use of didactic models for the teaching of genetics was analyzed, starting from the perspective of the biology professors of the state schools of the city of Planalto-PR. Initially three didactic models were constructed to be made available to the teachers, which were used to work on content that they listed as being more complex. The models were used in the classroom, and those involved reported the validity of the resources as didactic strategies, aiding in understanding the contents, as well as rescuing the students participation during the classes.
\end{abstract}

Key words: Genetics, Didactic Resource, Playful Learning.

\section{Introdução}

As dificuldades enfrentadas no processo de ensino-aprendizagem da Biologia são debatidas pelos estudiosos da área (SILVA, MORAIS E CUNHA, 2011). Dentre elas, professores e alunos, relacionam a utilização de termos técnicos, palavras desconhecidas, conceitos científicos, poucas aulas práticas e a escassez de recursos facilitadores.

Segundo Caneppa et al. (2015), diante de uma gama de conceitos relacionados à biologia,

\footnotetext{
${ }^{1}$ Discente do curso de Ciências Biológicas, Universidade Federal da Fronteira Sul, Campus Realeza.

${ }^{2}$ Graduada em Ciências Biológicas pela Universidade Estadual de Maringá (1998); pós-graduada em nível de mestrado no ano de 2003 e doutorado em 2007, titulações obtidas na Universidade Estadual de Maringá no Programa de Pós-graduação em Agronomia, área de concentração Melhoramento Genético Vegetal. Atualmente, professora da Universidade Federal da Fronteira Su 1- campus Realeza - PR.

${ }^{3}$ Graduação em Ciências Biológicas. Mestre e Doutora em Agronomia, área de concentração Melhoramento Genético. Professora Associado D (Nível I) da Universidade Federal da Fronteira Sul, desenvolvendo pesquisa com Toxicologia Comparada com foco em qualidade da água
} 
o estudante muitas vezes apresenta dificuldades para a compreensão dos conteúdos, o que leva a decorarem invés de compreender, não atingindo o objetivo do processo de ensino e aprendizagem. $\mathrm{O}$ autor, ainda reforça que, a situação se agrava quando requer conhecimento prévio de outros temas ou mesmo outras disciplinas, os quais não foram abordados.

Damis (1996) descreve a prática pedagógica no interior da sala de aula destacando a importância da relação professor-aluno e, reforça que a transmissão e a assimilação de um saber científico requer determinados meios, procedimentos e adaptações no processo de ensinar e aprender. Neste sentido o autor destaca também que, “[...] a didática em vez de tratar o como ensinar apenas como uma técnica, deve constituir-se também, como meio que contribui para a compreensão crítica da educação e do ensino" (DAMIS, 1996, p. 22).

O Governo do Estado do Paraná (PARANÁ, 2008) desenvolveu uma cartilha que trata das Diretrizes Curriculares da Educação Básica, onde se discute que a escola deve trabalhar com diferentes estratégias didáticas para o ensino e aprendizagem, e, que se incentive a prática pedagógica adotando a utilização de diversos métodos de ensino, para se fazer uma escola emancipadora de aprendizagem.

Retratando a prática pedagógica, Barni (2010) destaca que na sala de aula encontramos o espaço adequado para a construção de conhecimento, para as interações constantes, fato que contribui para a formação de pesquisadores. Contudo para que isso ocorra é importante trabalhar as dificuldades relatadas por parte dos alunos, de forma a viabilizar a compreensão dos conteúdos, mas também considerar as dificuldades advindas dos professores e que muitas vezes surgem durante o ensinar. Para a compreensão dos conteúdos, é importante que o professor não se restrinja a utilização do livro didático e textos, mas adote estratégias didáticas variadas, tais como: músicas, vídeos, imagens, jogos e modelos didáticos.

Além disso, outra preocupação é manter a atenção e a participação dos alunos em sala de aula. Segundo Tavares (2004) uma das alternativas é a utilização de estratégias de ensino que levem os alunos a uma aprendizagem significativa, processo por meio do qual um novo conhecimento relaciona-se de maneira substantiva, não-literal e não-arbitrária a estrutura cognitiva do aluno.

Para Corpe e Mota (2014) o sistema educacional que existe nas escolas estabelece barreiras e para que elas sejam destruídas, o professor deve desenvolver métodos pedagógicos diversificados que ajudem na aprendizagem dos alunos. Caneppa et al. afirma que:

[...] o uso dos modelos didáticos e outras atividades lúdicas como ferramentas podem ser essenciais e eficientes na facilitação do aprendizado nas diferentes áreas da biologia e da saúde, principalmente em temas relacionados à anatomia e fisiologia que exigem abstração e conhecimento de diferentes conceitos 
(CANEPPA et al. 2015, p. 3).

Assim, a aprendizagem mediada por modelos didáticos estimula o envolvimento da teoria com a prática em uma dimensão lúdica (VALOIS et al., 2010). De acordo com Miranda (2002), professores relatam a motivação em sala de aula ao incluir atividades lúdicas como ferramentas metodológicas, os estudantes demonstram entusiasmo e interesse, consequentemente, com aprendizagem significativa.

Para Orlando et al. (2009), durante o ensino médio, a biologia celular e molecular integram conteúdos com conceitos abstratos e estruturas microscópicas. Tais dificuldades podem ser amenizadas pela elaboração de material didático de apoio. Os modelos didáticos como ferramenta permitem a manipulação do material, favorecem o entendimento da estrutura trabalhada, facilitam a compreensão e contribuem para a consolidação da aprendizagem.

Diante do exposto e, sob a perspectiva dos professores do ensino médio que ministram aulas para a disciplina de biologia nas escolas estaduais do município de Planalto - PR, este estudo buscou compreender e estabelecer estratégias para sanar as dificuldades tanto de aprendizagem dos alunos, quanto para facilitar o trabalho dos professores ao ensinar, tendo como mecanismo principal desenvolver modelos didáticos para utilização como recursos facilitadores no processo de ensino e aprendizagem.

\section{Metodologia de Pesquisa}

A pesquisa, aprovada pelo Comitê de Ética em Pesquisa da Universidade Federal da Fronteira Sul sob o número 2.636.219, constou de questionários semi estruturados de cunho qualitativo, aplicados para três professores (P1, P2 e P3) da disciplina de biologia, que ministram aulas de genética em duas escolas estaduais do Município de Planalto - PR.

A condução dos trabalhos foi dividida em dois momentos: 1) aplicação do questionário inicial (ANEXO 1), para orientação na construção dos modelos didáticos; 2) aplicação de um questionário final (ANEXO 2), para avaliação da utilização da atividade lúdica no processo de ensino e aprendizagem.

\section{Aplicação do Questionário Inicial e Construção dos Modelos Didáticos}

O questionário inicial foi aplicado para conhecer os professores envolvidos e constou das seguintes informações: a formação do professor, a jornada de trabalho cumprida semanalmente, o tempo de trabalho na docência, o número de turmas que ministra aula de genética, o número de escolas em que trabalha e em quantos períodos ministra aulas, a experiência na disciplina em outros momentos, se ele faz uso de modelos didáticos, além de saber em quais conteúdos 
relacionados à genética percebe um nível de dificuldade maior para o ensino e aprendizagem e quais as metodologias de ensino que os mesmos já haviam trabalhado em sala de aula.

Após reunir as informações dos professores e identificar os temas que relacionaram como mais complexos para ensinar, foram elaborados e construidos modelos didáticos, posteriormente, disponibilizados aos professores das escolas para aplicação em sala de aula.

\section{Aplicação do Questionário Final}

Após a utilização do recurso, os professores foram questionados sobre a contribuição dos modelos didáticos no processo de ensino e aprendizagem. Momento em que foi aplicado o segundo questionário, composto por seis questões, investigando sobre: o momento da aplicação dos modelos didáticos, a construção do recurso, a validade para a explicação dos conteúdos, as dificuldades encontradas pelos professores ao utilizar os modelos disponibilizados, a intenção de reutilização dos modelos em outras ocasiões, e, o desenvolvimento de outros modelos didáticos para o ensino de genética.

\section{Resultados}

No resultado obtido para os primeiros questionários foi possível identificar que todos os professores entrevistados tinham sua formação inicial em Ciências Biológicas, dos quais dois trabalhavam há mais de dez anos na docência e o outro, aproximadamente, cinco anos. Para o contrato de trabalho, dois eram 40 horas semanais e o terceiro com 10 horas semanais.

Todos registraram que trabalham em mais de uma escola e ministram aulas em dois ou mais períodos (manhã, tarde e/ou noite). Nas respostas, constaram já ter trabalhado com a disciplina de biologia em turmas anteriores e, que as aulas eram conduzidas com a utilização de slides, imagens projetadas, alguns experimentos, uso de modelos didáticos prontos, vídeos, uso de microscópios, construção de modelos didáticos e realização de pesquisas online.

Especificamente para a genética, relataram encontrar dificuldades para trabalhar os conteúdos das doenças herdáveis, genótipos e as leis de Mendel, mas que para o ensino de outros conteúdos, modelos já haviam sido utilizados. Assim, diante da relação dos conteúdos apontados como sendo de maior dificuldade para ensinar, foram desenvolvidos modelos didáticos, conforme descrito:

\section{1) Cariótipo gigante}

Para a construção do cariótipo gigante foi utilizado um quadro com base de papelão coberta por papel camurça, medindo $150 \times 106 \mathrm{~cm}$, e, para os cromossomos foram utilizados jornais revestidos com barbante e velcro para a fixação no quadro.

Foram construídos vinte e dois pares de cromossomos autossômicos e dois pares de 
cromossomos sexuais (Imagem 1). Também foram construídos alguns cromossomos excedentes para trabalhar cariótipos e exemplificar os mapas genéticos de portadores de síndromes (Imagem 2).

Na projeção dos cromossomos foram considerados o tamanho e a posição do centrômero para atender a formação dos grupos (A, B, C, D, E, F e XX ou XY) na formação do cariótipo.

Imagem 1 - Modelo didático: Cariótipo Gigante

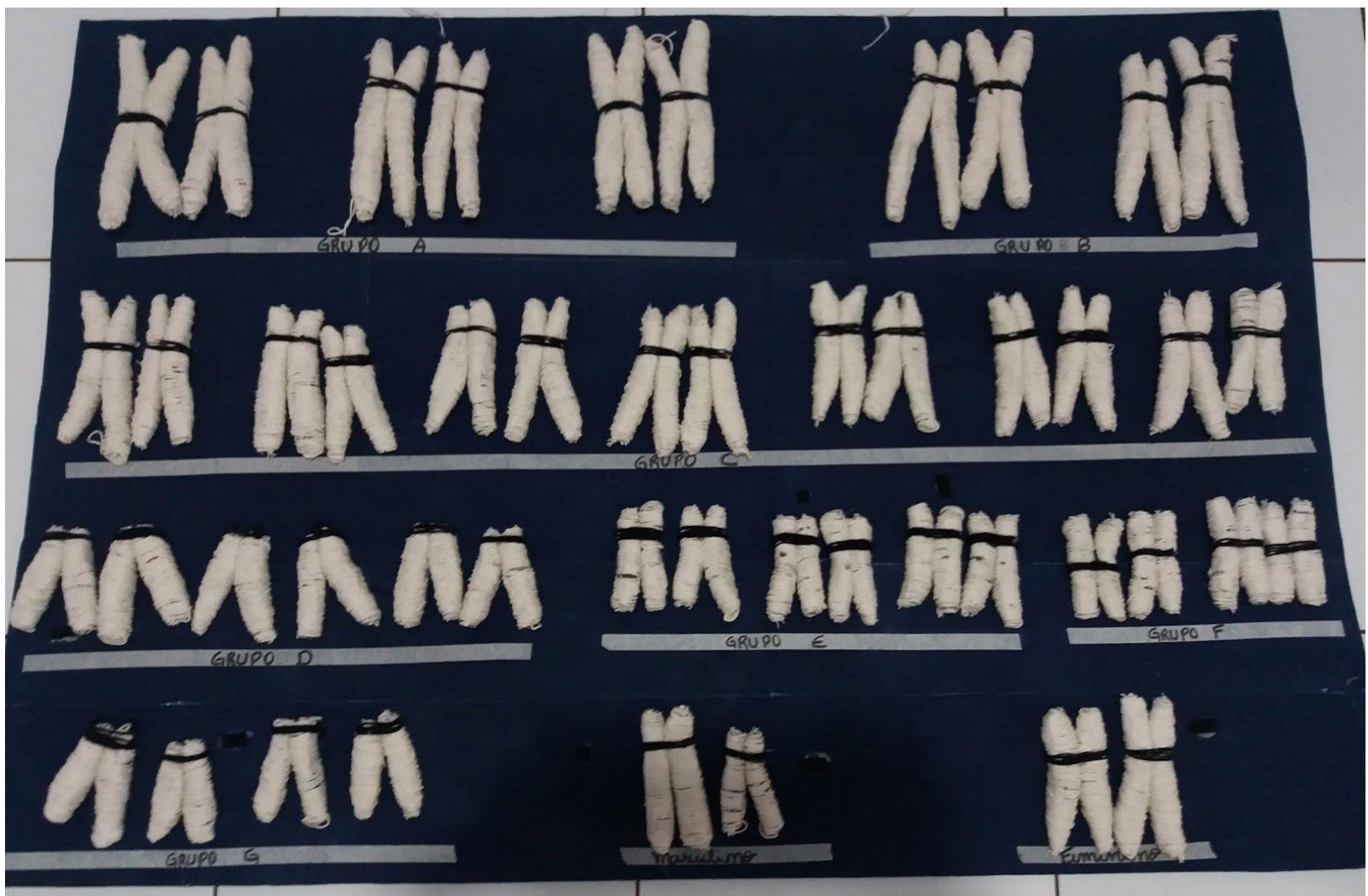

Fonte: Welter, 2018.

O velcro utilizado nas estruturas cromossômicas possibilitou trabalhar as diferentes configurações de cariótipos, dentre as quais: cariótipo normal e cariótipos para portadores de síndromes, como: Down (trissomia do cromossomo 21), Patau (trissomia do cromossomo 13), Edward (trissomia do cromossomo 18), Klinefelter (47 XXY), Duplo Y (47 XYY) e Triplo X $(47 \mathrm{XXX})$.

Além das alterações cromossômicas numéricas representadas pelas conhecidas trissomias, o modelo também possibilitou trabalhar alterações estruturais, pois um pedaço de cromossomo foi confeccionado para permitir aumentar um dos braços dos cromossomos existentes e exemplificar possibilidades para duplicação, translocação e perdas de segmentos cromossômicos, que também podem culminar em sérios problemas como malformações ou aberrações cromossômicas (MUSTACCHI; PERES, 2000). 
O modelo ainda permitiu explicar a estrutura e classificação dos cromossomos.

Imagem 2 - Cromossomos para trabalhar o conteúdo relacionado às síndromes

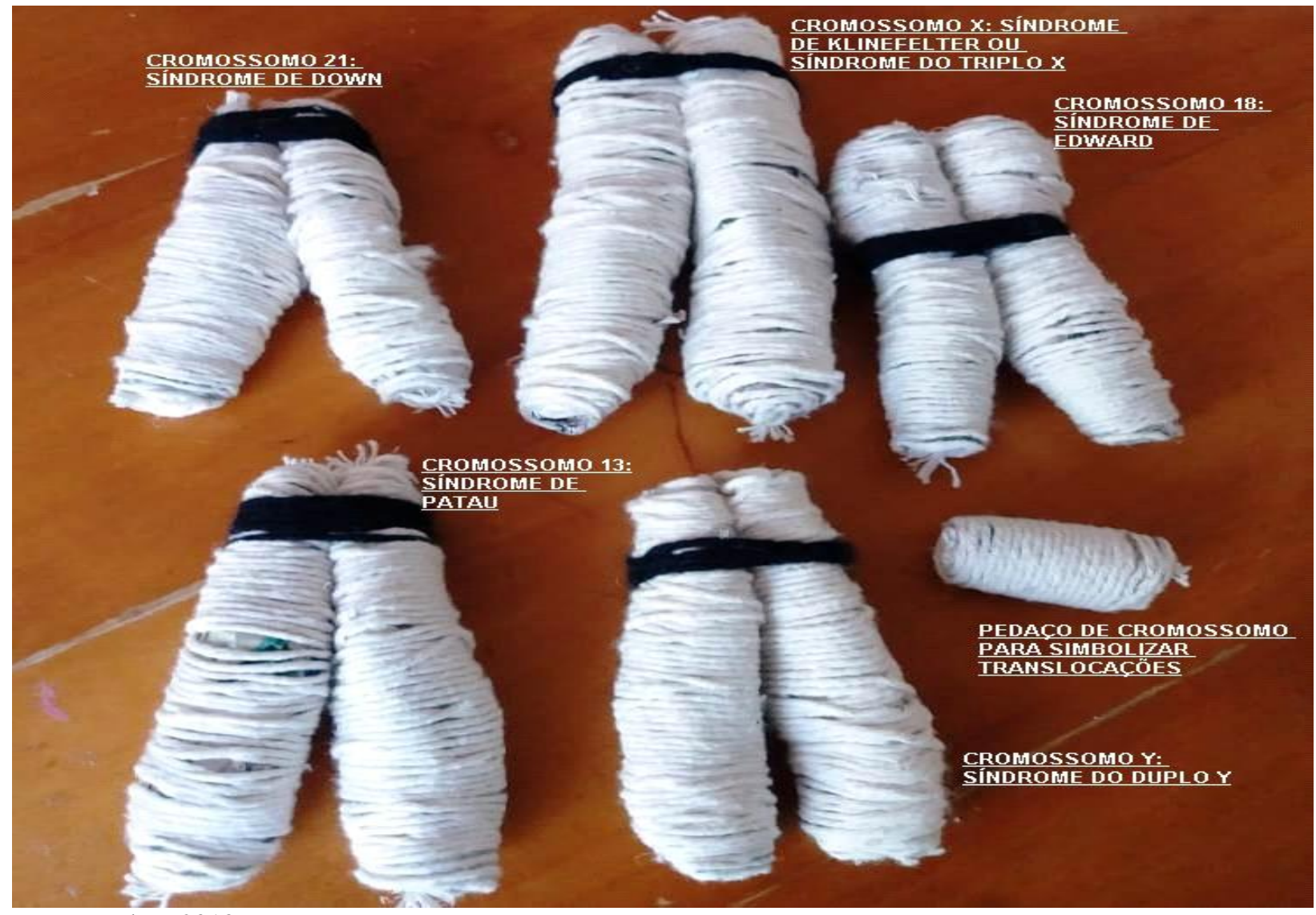

Fonte: Welter, 2018

\section{2) Os cromossomos e o seu genótipo}

O segundo modelo didático foi elaborado para trabalhar as combinações alélicas dos genes. Os 47 cromossomos foram desenvolvidos em material de EVA (acetato-vinilo de etileno) na cor amarela e cinza, dos quais um simbolizava o cromossomo X (sinalizado com letra $\mathrm{X}$ ), um o cromossomo Y (sinalizado com a letra Y), e os 44 cromossomos restantes, os autossômicos, sendo a metade marcada pela letra $\underline{\mathrm{A}}$ (maiúscula) e metade pela letra a (minúscula) (Imagem 3).

O objetivo deste modelo, baseado no trabalho de Temp (2011), foi formar combinações gênicas a partir da retirada aleatória de dois cromossomos de dentro de uma caixa e dizer qual o genótipo formado na combinação alélica, se heterozigoto ou se homozigoto recessivo ou homozigoto dominante. Para a definição do sexo do indivíduo, o cromossomo $\mathrm{X}$ ou o Y era apresentado pela professora e os estudantes concluiam com a construção do cariótipo. 
Imagem 3 - Modelo didático: Os cromossomos e o seu genótipo

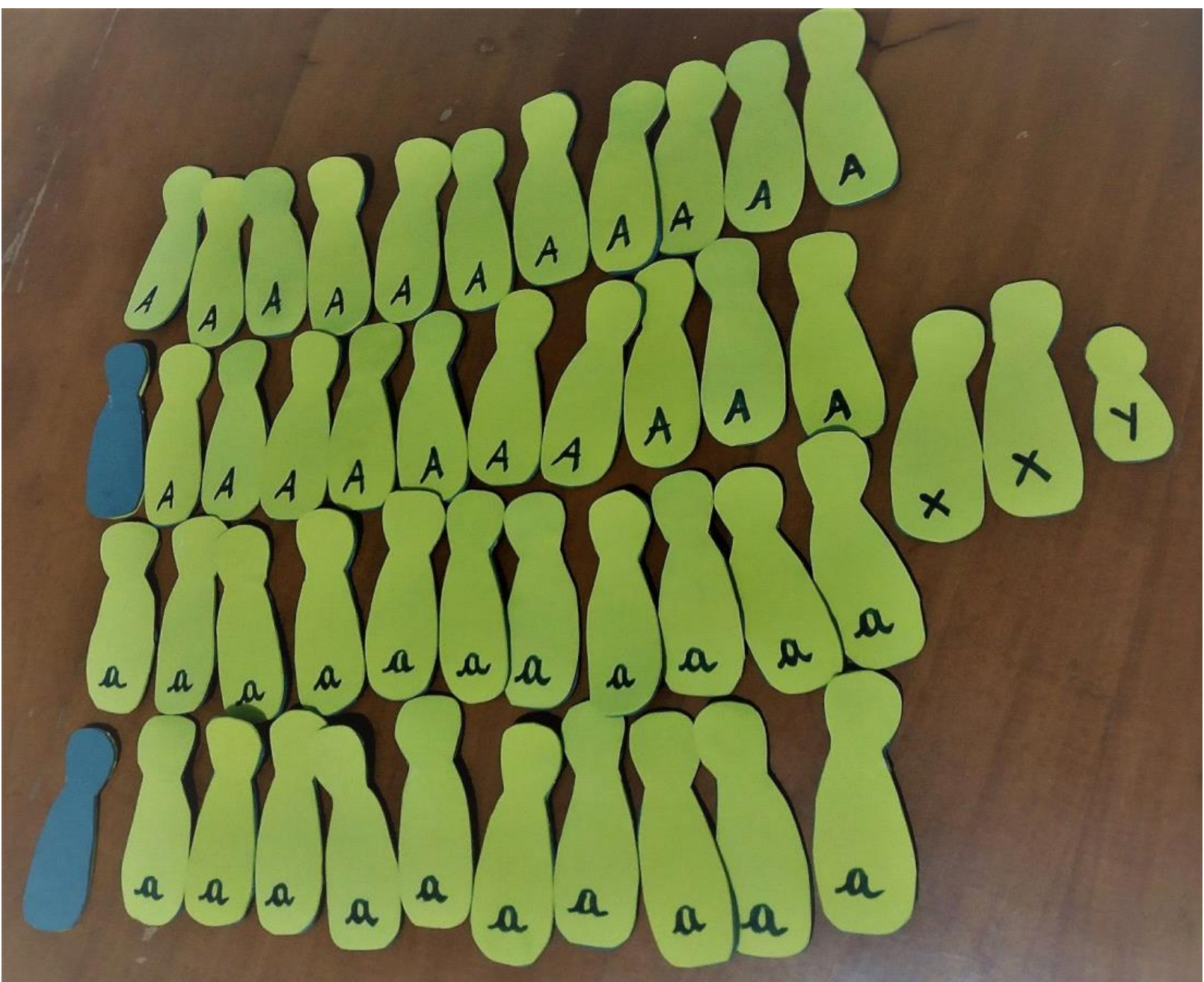

Fonte: Welter, 2018.

\section{3) Quadro da Segunda lei de Mendel}

O terceiro modelo didático foi elaborado para demonstração da Segunda Lei de Mendel. Nesta ferramenta de ensino foram utilizados quatro quadros de isopor medindo $25 \times 25 \mathrm{~cm}$ encapados com EVA branca, representando o genograma utilizado na explicação da Segunda Lei de Mendel. Para representar as ervilhas verdes e amarelas, lisas e rugosas, foram utilizados alfinetes com miçangas variando nas cores e texturas (Imagem 4).

Para trabalhar com o modelo foram definidos quatro grupos de alunos, os quais estabeleciam o cruzamento a partir dos genótipos apresentados na parte superior do quadro, isto é, $\mathrm{AaBb}$ x $\mathrm{AaBb}$. $\mathrm{Na}$ resolução do genograma, os estudantes utilizavam os alfinetes para simbolizar as ervilhas e facilitar o entendimento de conceitos como, fenótipo e genótipo, bem como a importância dos cruzamentos. 
Imagem 4 - Modelo didático: Quadro da Lei de Mendel

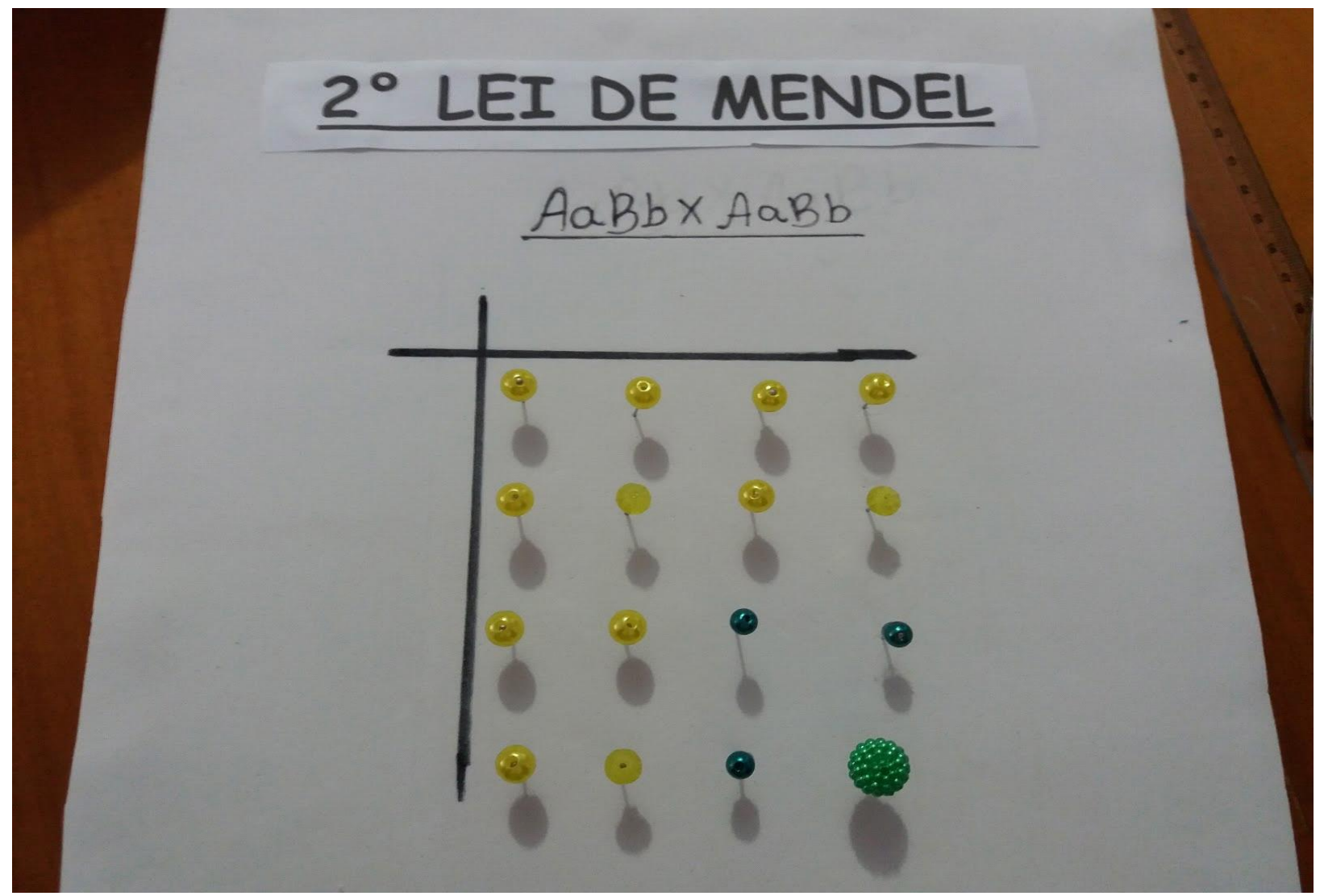

Fonte: Welter, 2018.

Após a utilização dos modelos didáticos, os professores responderam o questionário final e socializaram os resultados obtidos a partir da utilização dos recursos utilizados para trabalhar os conteúdos de genética.

O primeiro modelo didático foi aplicado pelos três professores e as expectativas foram atingidas. O professor P1 relatou: "a turma em si é muito conversadora e os alunos têm dificuldade em prestar atenção, no entanto, o modelo didático prendeu a atenção deles, eles apresentaram muito interesse, realizaram vários questionamentos e participaram da aula". Para o professor P2: "o modelo foi válido, pois aumentou o interesse dos alunos pela aula de genética". A experiência relatada pelo professor P3 foi que: "sim foi válido, pois através da atividade prática o aluno associou melhor o conteúdo que estava sendo trabalhado somente na parte teórica".

Para os avanços que o primeiro modelo didático possibilitou aos alunos, o professor P1 relatou: "os alunos compreenderam as síndromes facilmente, tenho certeza que não ocorreu somente o ensino, mas também o aprendizado". Para o professor P2 "os alunos entenderam com maior clareza, participaram da aula com entusiasmo, pois a visualização dos cromossomos facilitou a compreensão dos alunos". A opinião do professor P3 foi: "sim, o modelo facilitou o 
aprendizado, associando a parte prática com a parte teórica conseguindo atingir os objetivos propostos".

Quanto à construção de mais modelos didáticos para o ensino de genética o professor P1 respondeu: "pelas experiências que os modelos didáticos proporcionam e pela percepção do lúdico para o aprendizado irei me esforçar para ser criativa e desenvolver outros modelos didáticos". O professor P2 relatou: "irei construir sim, para explicar os grupos sanguíneos, fator Rh, segregação dos fatores entre outros". Já o professor P3 respondeu: "irei construir mais modelos didáticos, pois são importantes para o aprendizado do aluno e, a partir das atividades práticas o conteúdo se torna mais fácil para o aluno entender".

O segundo modelo didático foi aplicado pelo professor P2 e foi avaliado como sendo um instrumento facilitador do processo de aprendizagem, possibilitando a integração e maior participação dos alunos. Ele descreveu que: "houve avanço na aprendizagem dos alunos ao final da aplicação, pois eles entenderam com maior clareza o conteúdo". Ainda relatou que não encontrou dificuldades para aplicar o recurso e que utilizaria novamente. Também sinalizou sobre a intenção de construir outros modelos e relatou que: "sim, pois os mesmos auxiliam no aprendizado dos alunos do ensino médio".

O terceiro modelo didático foi aplicado pelo professor $\mathrm{P} 3$, e sobre o recurso didático ter sido válido na aprendizagem dos alunos relatou: "sim, porque o modelo foi bem prático e os alunos entenderam as combinações genotípicas formadas entre os cruzamentos dos gametas". Sobre os avanços na aprendizagem dos alunos descreveu: "houve avanços, com o desenvolvimento dos cruzamentos com atividade prática onde os alunos observaram os resultados e combinações dos genótipos, gerando sementes de diferentes cores e texturas". Relatou que não houve dificuldades na aplicação do recurso e que faria uso novamente para trabalhar o conteúdo. Quanto à elaboração de outros modelos para o ensino de genética descreveu: "iria construir sim, pois facilitam o aprendizado do aluno".

Todos os professores relataram não terem tido dificuldades na aplicação dos modelos e que fariam uso novamente, quando pudessem.

\section{Discussão}

A introdução aos estudos de biologia começa no ensino fundamental com o aprofundamento dos conceitos ensino médio, período em que muitos alunos apresentam dificuldades de aprendizagem sobre os conteúdos, decorrente de muitos termos e conceitos novos e abstratos (BADZINSKI; HERMEL, 2015). Tais dificuldades podem ser minimizadas pelo professor por meio de práticas pedagógicas que forneçam ao aluno a aprendizagem 
necessária sobre esses conteúdos, pois segundo Rocha (2013)

O processo de ensino - aprendizagem, não deve restringir ao contexto escolar. Diferentes espaços podem e devem ser explorados assim como, metodologias diferenciadas e novas propostas pedagógicas, podem ser pensadas para uma melhor qualidade de ensino (ROCHA, 2013, p. 17)

Neste contexto, Orlando et al. (2009) destaca a importância da formação do professor na área de atuação, como sendo um critério facilitador na construção dos conhecimentos técnicos e didáticos, garantindo a qualidade da aula, a construção de conhecimentos essenciais e uma visão crítica sobre o processo de ensino e aprendizagem.

Araújo e Gusmão (2017) reforçam que a má formação do professor e o seu despreparo dificultam a aprendizagem e o ensino de genética. Como consequência surge as dificuldades no ensinar e a ineficácia da aprendizagem dos alunos.

Sobre a formação, todos os entrevistados neste trabalho responderam que são graduados em Ciências Biológicas e que apresentam experiência de no mínimo cinco anos na docência.

A informação referente ao tempo no magistério leva a duas reflexões, a primeira é de que o professor com anos de formação e atuação não trabalharia com modalidades didáticas dentro da sala de aula, por não estar acostumado com esses recursos metodológicos, e a segunda que o professor formado recentemente e há menos tempo na docência contaria na sua formação com mais estratégias didáticas para trabalhar em suas aulas.

Porém ao observar a realidade de trabalho dos professores, pode-se analisar que as modalidades didáticas utilizadas pelos entrevistados eram baseadas nos recursos: lousa, slides, textos, vídeos e modelo didáticos prontos, ou seja, uma abordagem tradicional. Hoje, para obter sucesso no ensinar, o professor precisa considerar que a sua formação é um processo constante, que exige reformulações de estratégias para trabalhar conhecimentos iniciais e práticas inseridas na vivência dos estudantes, mostrando dedicação e que a sua personalização vai ocorrendo com o passar do tempo (NUNES, 2001).

Quanto aos modelos didáticos utilizados pelos professores em sala de aula, na maioria das vezes são descritos como tradicionais e aplicados para finalizar algum conteúdo. Neste sentido, Pliessing e Kovaliczn (2009) relatam que alguns professores se preocupam com as medidas pedagógicas diferenciadas, adotam práticas que vão além de aula expositiva com uso somente do quadro e do livro didático, mas que nem sempre isso acontece devido a alguns fatores como "[...] desinteresse dos alunos e o despreparo ou também desinteresse por parte do professor em capacitar-se para utilizar outros recursos e metodologias" (PLIESSING; KOVALICZN, 2009, p. 18), eles também ressaltam que: 
Romper esse círculo vicioso: formação acadêmica deficiente, uso de metodologias inadequadas, desinteresse por parte dos alunos, estagnação no processo de formação continuada, depende em grande parte da intervenção do próprio professor na sua prática pedagógica. (PLIESSING; KOVALICZN, 2009, p. 18).

É sabido que além da formação inadequada de alguns profissionais, outros fatores também interferem no processo de diversificação metodológica e estão relacionados às exaustivas jornadas de trabalho, necessárias para prover o sustento do profissional e de seus familiares, como: o número de aulas assumidas; a falta de tempo extra para preparar materiais na escola, já que as horas-atividades são direcionadas a correção de atividades e lançamentos exigidos nos sistemas escolares; aos inúmeros deslocamentos que o professor faz de uma escola para a outra, já que é uma condição necessária para manter seu contrato de trabalho.

Para os entrevistados, o tempo para preparo de modelos didáticos foi um fator agravante. Ao estabelecer o comparativo para a carga horária dos professores, foi comum para dois deles a jornada de 40 horas semanais, em mais de uma escola e em dois turnos ou mais.

Segundo a Secretaria de Estado da Educação do Paraná (PARANÁ, 2018), o professor que tem o cargo de 40 horas semanais trabalha 30 aulas de 50 minutos, correspondente a 25 horas de interação direta com o educando. Assim, resta apenas nove horas para atividades extraclasse. Diante de uma rotina exaustiva, pouco tempo sobra para preparo de aulas, lembrando que nos intervalos o professor necessita de deslocamentos entre uma escola e outra para cumprir sua jornada, inviabilizando ou dificultando o trabalhar ou construir algo para usar, além do livro didático.

Observa-se ainda que a maioria dos professores, por mais que já estejam anos na docência, encontram dificuldades em explicar alguns conteúdos. Segundo Goulart e Faria (2014) essas dificuldades em ensinar, transmitir e acompanhar as produções científicas atuais dificultam a convivência e o ensino em sala de aula, por isso a utilização de práticas educativas que atraiam a atenção do aluno.

A concepção dos professores referente aos modelos didáticos construídos e aplicados foi de que são importantes para a aprendizagem dos alunos e válidos para o ensino dos conteúdo. Orlando (2009) em seu trabalho sobre o uso de modelos didáticos para o ensino de genética, relata a importância desta metodologia de ensino para a capacidade assimilativa, associativa e de memorização e, assim o momento da explicação muito mais descontraído e interessante para os alunos.

Temp (2011, p. 47) relata que "o uso de metodologias alternativas, como os modelos didáticos, são formas eficazes para auxiliar a aprendizagem quando os conteúdos são abstratos e exigem que os alunos e professores possuam capacidade de abstração e imaginação". Que o 
aluno ao manusear materiais didáticos e lúdicos, irá simplificar o conceito e facilitar a assimilação do conteúdo.

Orlando (2009), atribui aos modelos didáticos a representação da teoria abstrata dos livros, e a sua aplicação em sala de aula leva a um maior interesse pelo conteúdo, além de possibilitar que o aluno possa ir para além da sala de aula, por meio de pesquisas.

A percepção desse envolvimento coletivo foi relatada pelos professores participantes da pesquisa, os quais sinalizaram que, sempre que possível, se preocuparão em desenvolver modelos didáticos, pois verificaram o quanto este recurso favoreceu o trabalho de assuntos complexos e abstratos, como alguns dos conceitos genéticos, os cariótipos, as doenças, o estudo dos genes e suas probabilidades. Também perceberam a relação positiva dos modelos didáticos no processo de aprendizagem e o envolvimento dos alunos nas atividades propostas.

Rocha (2013) afirma que:

[...] a utilização de diferentes materiais e metodologias no processo de ensino e aprendizagem em genética são capazes de aumentar o interesse dos alunos em relação aos conteúdos dessa matéria. Visto que a mesma é composta de assuntos abstratos diversos e de difícil assimilação pelos alunos, torna-se, por vezes, distante da realidade dos mesmos. Dessa forma é imprescindível que a teoria e a prática caminhem paralelamente no desenvolvimento do trabalho do professor em sala de aula, facilitando assim o processo de ensino e aprendizagem (ROCHA, 2013, p. 26).

Diante dos relatos bibliográficos e da concepção dos professores que participaram deste trabalho, modelos didáticos são indicados para que as escolas adotem como recurso didático no ensino de genética e em outras áreas de conhecimento, possibilitando aos alunos melhor entendimento e aprendizagem dos conteúdos e, favorecendo a integração aluno-professor.

\section{Considerações Finais}

Os modelos didáticos construídos, apesar de requerer tempo para a sua produção, são de fácil construção, baixo custo e viáveis tanto para o professor quanto para a escola. Na sala de aula são recursos facilitadores no processo de ensino e aprendizagem.

A utilização do recurso pelos envolvidos no processo, professores e alunos, foi satisfatória e a experiência positiva ao descrever a facilidade de compreensão de conteúdos complexos da genética, além de destacarem que contribuiu para aulas mais atrativas e para a consolidação do aprendizado.

\section{Referências}

ARAÚJO, A. B.; GUSMÃO, F. A. F. As principais dificuldades encontradas no ensino de genética na educação básica brasileira. In: ENCONTRO INTERNACIONAL DE 
FORMAÇÃO DE PROFESSORES, 10., 2017, Aracaju. Artigo. Aracaju: Grupo Tiradentes, 2017. p. 1 - 12.

BARNI, G. S. A importância e o sentido de estudar genética para estudantes do terceiro ano do ensino médio em uma escola da rede estadual de ensino em Gaspar(SC). 2010. $184 \mathrm{f}$. Dissertação (Mestrado) - Curso de Programa de Mestrado Profissional em Ciências Naturais e Matemática da Universidade Regional de Blumenau, Universidade Regional de Blumenau, Blumenau, 2010.

BADZINSKI, C.; HERMEL, E. do E. S. A representação da genética e da evolução através de imagens utilizadas em livros didáticos de biologia. Revista Ensaio, Belo Horizonte, v. 17, n. 2, p.434-454, maio 2015.

CANEPPA, A. R. G. et al. Utilização de Modelos Didáticos no Aprendizado de Anatomia e Fisiologia Cardiovascular. Revista do Curso de Enfermagem, v. 1, n. 01, 2015.

CORPE, F. P.; MOTA, E. F. Utilização de Modelos Didáticos no Ensino-Aprendizado em Imunologia. Sbenbio, São Paulo, v. 1, n. 7, p. 2070-2080, out. 2014.

DAMIS, O. T. Didática e Sociedade: O conteúdo implícito do ato de ensinar. In: VEIGA, I. P. Alencastro et al. Didática: O ensino e suas relações. 18. ed. Campinas: Papirus, 1996. p. 9-31.

GOULART, N. M.; FARIA, R. C. B. Ensino de conteúdos de Genética no ensino médio e as contribuições dos objetos de aprendizagem. In: CONGRESSO IBERO-AMERICANO DE CIÊNCIA, TECNOLOGIA, INOVAÇÃO E EDUCAÇÃO, 1., 2014, Buenos Aires. Relato de experiências. Buenos Aires: Isbn, 2014. p. 1 - 9.

MIRANDA, S. de. No fascínio do jogo,a alegria de aprender. Linhas Críticas, Brasília, v. 8, n. 14, p.21-34, jan. 2002.

MUSTACCHI, Zan; PERES, Sergio. Estudo do cariótipo humano e principais cromossopatias. In: MUSTACCHI, Zan; PERES, Sergio. Genética Baseada em evidências. São Paulo: Cid, 2000. Cap. 6. p. 261-335.

NUNES, C. M. F. Saberes Docentes e Formação de professores: Um breve panorama da pesquisa brasileira. Educação e Sociedade, Campinas, v. 22, n. 74, p.27-42, abr. 2001.

ORLANDO, T. C. et al. Planejamento, Montagem e Aplicação de Modelos Didáticos para Abordagem de Biologia Celular e Molecular no Ensino Médio por Graduandos de Ciências Biológicas. Revista Brasileira de Ensino de Bioquímica e Biologia Molecular, Alfenas, v. 01, n. 01, p.1-17, fev. 2009.

PARANÁ, S. E. E. Diretrizes Curriculares da Educação Básica: Biologia. Paraná: Jam3 Comunicação, 2008. 76 p.

PARANÁ. Resolução N. ${ }^{\circ}$ 15/2018 - GS/SEED. Secretaria de estado da Educação do Paraná. Disponível

〈http://www.educacao.pr.gov.br/arquivos/File/resolucoes/2018/resolucao152018gsseed.pdf $>$.

Acesso em: 04 out. 2018.

PLIESSING, A. F.; KOVALICZN, R. A. Uso de metodologias alternativas como forma de superação da abordagem pedagógica tradicional na disciplina de biologia. 2009. Disponível em: 〈http://www.diaadiaeducacao.pr.gov.br/portals/pde/arquivos/1-4.pdf>. Acesso em: 08 out. 2018.

ROCHA, L. S. da. Estratégias metodológicas para ensinar genética no ensino médio. 2013. 47 f. Monografia (Especialização) - Curso de Pós-Graduação em Educação: Métodos e Técnicas de Ensino, Universidade Tecnológica Federal do Paraná, Medianeira, 2013.

SILVA, F. S. S. da; MORAIS, L. J. O.; CUNHA, I. P. R. Dificuldades dos professores de 
biologia em ministrar aulas práticas em escolas públicas e privadas do município de Imperatriz (MA). Revista Uni, Imperatriz, v. 1, n. 1, p.135-149, jan. 2011.

TAVARES, R. Aprendizagem significativa. Conceitos, João Pessoa, p.56-60, jun. 2004.

TEMP, Daiana Sonego. Facilitando a aprendizagem de genética: uso de um modelo didático e análise dos recursos presentes em livros didáticos de Biologia. 2011. 85 f. Dissertação (Mestrado) - Curso de Educação em Ciências: Química da Vida e Saúde, Centro de Ciências Naturais e Exatas, Universidade Federal de Santa Maria, Santa Maria, 2011.

VALOIS, R. S. et al. Trilhando conhecimento ecológico: Proposta de uma atividade lúdica de ecologia. Sbenbio, São Paulo, v. 1, n. 3, p.3930-3938, out. 2010.

\section{ANEXOS:}

\section{Anexo 1: Questionário inicial}

1) Qual a sua formação profissional?

( ) Ciências Biológicas ( ) Física ( ) Química ( ) Outros

2) A quanto tempo você trabalha com a docência no ensino médio?

( ) 1 a 5 anos ( ) 5 a 10 anos ( ) Mais de 10 anos.

3) para quantas turmas ministra aulas de genética?

4) O contrato de trabalho é de quantas horas semanais?

( ) $20 \mathrm{hs} \mathrm{(} \mathrm{)} 40 \mathrm{hs}$

5) Trabalha em mais que uma escola?

( ) $\operatorname{Sim}($ ) Não

6) Quantos períodos você ministra aulas?

( ) Até 2 períodos ( ) Mais de dois períodos

7) Já ministrou essa disciplina para turmas anteriores?

( ) Sim ( ) Não

8) Quais as metodologias que você utiliza para o ensino de genética?

9) Na disciplina, qual (ais) conteúdo (os) identificou como sendo mais difícil o ensino e aprendizagem?

10) poderia informar se já trabalhou com modelos didáticos? Em quais disciplinas ou conteúdo?

( ) $\operatorname{Sim}($ ) Não

Quais:

\section{Anexo 2: Questionário final}

1) Em qual conteúdo você utilizou o modelo didático?

2) Na sua opinião foi válido a utilização do modelo disponibilizado pela aluna para o ensino desse conteúdo?

3) Poderia informar se identificou avanços na aprendizagem dos alunos com o uso do 
modelo? Qual(ais)?

4) Encontrou dificuldades na aplicação do modelo didático? Qual(ais)?

5) Faria o uso desse modelo sempre que tivesse que ministrar esse conteúdo em sala de aula?

( ) Sim ( ) Não

6) Poderia informar se desenvolveria outros modelos didáticos, tanto para esse conteúdo como para outros conteúdos relacionados a genética?

Recebido em 29/03/2019 - Aprovado em 15/06/2019 